\title{
Learning activities in the University of Rwanda's distance teacher education materials: some lessons for designers
}

Emmanuel Sibomana

The Wellspring Foundation for Education, University of Rwanda-College of Education, Rwanda

\section{Vol 1 No 12019}

ISSN: 2788-6298

DOI: https://doi.org/10.35293/tetfle.v1i1.68

\begin{abstract}
Learning activities constitute a very important component of distance education materials. They are associated with active learning and learning by doing, which are widely accepted as effective learning approaches. Learning by doing is particularly significant in distance education because distance learners have to teach themselves or learn on their own through doing and reflecting. This article reports and reflects on research which focused on the distance education materials designed by the University of Rwanda's College of Education to provide professional development opportunities for high school teachers of English in Rwanda. Findings from a textual analysis of the materials and from interviews with a sample of teachers who had used these materials indicate that most of the activities were designed solely for 'assessment of learning' purposes and encourage a surface approach to learning. It is argued that activities which encourage a surface approach to learning limit learners' engagement with, and understanding of, the content in the materials and improvement in quality teaching, a key goal of teacher professional development.
\end{abstract}

Keywords: Distance teacher education, learning activities, approaches to learning, assessment

CONTACT Emmanuel Sibomana @ esibomana1@gmail.com 


\section{Introduction}

Learning activities are an integral part of teaching (Lockwood 1992) and refer to the tasks given to learners by the teacher in order to help them learn actively. They play an important role in distance education (DE). For Race (1992, 61, capitals in the original text) "the quality of an open learning module is closely connected to the quality of the things learners DO while using it" and for Lusunzi $(1999,4)$, "the use of instructional activities to effect better distance teaching is not optional, but mandatory". As noted by Biggs and Tang (2009), Kember (1996) and Struyven et al. (2002), the learning approaches which learners adopt are influenced by the nature of the activities. In their study, Struyven and colleagues (2002) found that learners adapted their learning to the demands that they were exposed to in activity questions. Thus, care needs to be taken to produce high quality learning activities which engage "self-directed learners" (Bordeau \& Bates 1996, 268). This article reports and reflects on the teaching/learning activities in distance education materials designed by the University of Rwanda's College of Education (UR$\mathrm{CE})$ for high school teachers of English and the kinds of learning approaches which they encourage.

UR-CE, formerly known as Kigali Institute of Education (KIE), was created in 1999 to address the shortage of qualified high school teachers in Rwanda. In 2001, with limited experience in offering distance education, it started the first DE programme in Rwanda for under-qualified in-service high school teachers. This mode of education was chosen for these teachers because their number was so high that they could not be all taken out of schools and offered on-campus professional development; there were no other teachers to replace them. The beneficiaries were mainly teachers in rural areas with limited chances and means of joining on-campus, evening or weekend degree programmes. They volunteered for the programme because, in addition to increasing their knowledge and helping them teach better, getting a degree would make them qualified, would make their jobs secure, and would result in an increase in their salary.

This programme used printed materials as the main teaching/learning resource, supplemented by bi-annual face-to-face sessions with UR-CE lecturers and monthly 


\section{E. SIBOMANA}

tutorials with regional subject tutors who are university graduates in the respective subjects. The aims of these print materials were three-fold: (i) to help in-service secondary school teachers acquire more subject knowledge, (ii) to develop their analytical and reflective skills and (iii) to improve the quality of their teaching (KIE 2009, 1). The materials designers were full-time lecturers at KIE and designing these materials was an 'add-on' to already heavy workloads. The designers were mainly subject specialists and had limited experience in designing DE materials (KIE 2009). These factors are likely to have had a bearing on the quality of the materials. This paper aims at addressing the following research questions:

1. What role do learning activities play in UR-CE DE materials for teachers of English?

2. What learning approach is encouraged in UR-CE DE materials for teachers of English and what are the related implications for learning?

3. What are the teacher-learners' perceptions of learning activities in UR-CE DE materials for teachers of English?

\section{Literature Review}

The focus of the short literature review is on (1) the rationale for including activities in distance education materials, (2) surface and deep learning, two learning approaches which can be encouraged by these activities, and (3) the implications which these materials and approaches have for learning.

Distance education materials constitute one type of self-instructional materials or texts. Self-instructional materials facilitate individualised learning and are appropriate for learners who study mostly on their own. Writers of DE materials (e.g. Biggs \& Tang 2009; Howard \& McGrath 1995; Lockwood 1992; Phillips 2007; Race 1992; Rowntree 1990) emphasise the importance of learning activities in the teaching/learning process. According to Howard \& McGrath $(1995,9)$, activities should provide students "with feedback on the effectiveness of their processing". They should also encourage learners to learn actively and to apply and reflect on what is learned and its implications (Lockwood 
1992; Race 1992). A key finding from Lockwood's investigation of student response to DE materials was that students regard activities as "contributing to their understanding of the course content, the particular ideas, relationships, procedures and techniques that are at the centre of the teaching" (Lockwood 1992, 100). In short, learning activities play a central role in learning outcomes in distance education because, as Smith and Smith (2006) indicate, a good number of distance education learners gear their reading primarily to learning activities.

Activities include all instances where learners are instructed to do something which may or may not require an explicit and/or written answer which needs to be marked. For example, teacher-learners may be required to try a new way of teaching in their classrooms and to reflect on a certain scenario in the classroom or their community. Questions constitute a frequently used type of activity but are not the only possible activity type. Where activities include questions, these can be of two main types: (1) SelfAssessment Questions (SAQs) and (2) In-Text Questions (ITQs). Rowntree (1990) notes that the former may appear severally together at the end of approximately an hour of reading in order to test understanding. Race (1992) considers SAQs to be the most important single factor that leads to successful learning from DE materials while for Rahman (2015), these questions are important for activating learning. Self-assessment questions can be designed for both formative and summative assessment purposes with the former being particularly important in the process of learning something new.

ITQs are rhetorical questions used at frequent intervals to create a dialogue between the instructional materials and the learner (Lusunzi 1999) and between the designer and the learner; they should make conversation flow and promote interactive learning (Rowntree 1990; Shabani \& Okebukola 2001). The teacher (DE materials writer) may build on possible answers to the ITQs in order to introduce and teach new content rather than merely using SAQs to check how much learning has occurred. As Fung $(2005,182)$ indicates, appropriate in-text activities in DE materials for teachers can help "teachers to think from a variety of perspectives and to relate theory to practice". 


\section{E. SIBOMANA}

Lockwood (1992) suggests that if students understand why the activities are worth completing, they are more likely to invest in these. Indeed, one reason for students skipping activities, according to Mishra and Gaba (2001), is the trivial nature of some of these. Clarity of activity questions and related instructions also encourage students to attempt the activities in self-instructional texts. According to Swales (2000), activities and accompanying instructions should be unambiguous, and the questions should be answerable especially because distance education learners mostly study alone (Phillips, 2007). Another feature of activities that can increase the likelihood of learners attempting them is diversifying activities to meet individual needs and study styles (Fung 2005), as people use different styles to learn and, within each learning style, at different paces (Christensen, Horn \& Johnson 2008). Activities should also make various intellectual demands on learners (Lockwood 1992) and avoid the boredom which may result from dealing with the same type of activity (Rowntree 1990). Variety in activity questions and tasks also encourages learners to use different skills, think from different perspectives and at different levels (Lockwood 1992). In short, activities should offer a balance between brief activities and lengthy ones, those requiring written answers and those merely requiring thoughts, closed questions and open questions (Rowntree 1990).

If it is accepted that the purpose of education is to stimulate inquiry skills and knowledge creation rather than encouraging learners to memorise a body of knowledge (Jordan \& Pillay 2009), DE materials designers should set activities that encourage learners to go beyond memorisation. While different types of questions and other activities are needed to cater for diversity, I suggest that the questions which require a low level of creativity and criticality should be fewer than those recommended by Murdoch (1994) and Phillips (2007) which require the highest levels of creativity, interaction production and application of ideas to learners' work or personal life.

\section{The Four Roles/Resources Model}

Referring to the level of engagement and criticality expected from students reading to learn, Freebody and Luke (1990) developed a Four Roles/Resources Model while Biggs (1987) conceptualised deep and surface approaches to learning. Students' successful 
learning largely depends on their ability to read various teaching/learning materials successfully. This is more so in distance education where learners are expected to read the materials mostly on their own. Therefore, DE materials should engage readers in the critical reading of texts. Writing about critical engagement with texts, Freebody and Luke (1990) identified four roles of a successful reader as follows: code breaker (decoding the codes and conventions of a text), text participant (comprehending texts), text user (understanding the purpose of different texts for different cultural and social functions) and text analyst (understanding how texts position readers and listeners). A successful reader needs to play the above four roles in his or her engagement with texts (Freebody \& Luke 1990). In educational contexts, the extent to which learners play the four roles in reading educational texts will depend on, among other factors, what the learning (and assessment) activities require. Thus, reading and writing activities which are aimed at helping learners to learn should encourage them to get to the text-analyst level, which is related to critical thinking (Freebody \& Luke 1999), one of the prime aims of higher education.

\section{Deep and surface approaches to learning}

According to Warren (2004), approaches to learning describe what students do when they go about learning and why they do this in particular ways. In this regard, two approaches (a deep approach and a surface approach) have been identified by Biggs (1987). Warren (2004) indicates that deep learning involves a critical analysis of new ideas, leading to understanding and long-term retention of these for problem-solving in unfamiliar contexts. This approach is in line with a deep approach to learning which encourages people to create or construct their own new understandings or "individual interpretations of their experiences" (Zarei 2008, 282) linking what they already know and believe to the ideas, events, and activities which they come in contact with in their daily life (Tenenbaum et al. 2001). 


\section{E. SIBOMANA}

In contrast to deep learning, "surface learning is the tacit acceptance of information and memorisation as isolated and unlinked facts" (Warren 2004) ${ }^{1}$. Learners using this approach only read and/or listen and reproduce what they learn, usually without thinking much about what it means to them individually; thus they cannot understand it deeply and/or relate it to what they already know. Such students are unlikely to recognise the same matter presented differently or in a different context. Biggs (2003) argues that effective teaching should encourage learners to adopt deep learning approaches. In other words, learners need to be engaged in activities that require them to work with content rather than merely reading it (Rowntree 1990).

Given that the distance education learner is physically separated from the teacher (Abedi \& Badragheh 2011) and "the learning materials take over some of the traditional role of the teacher" (Robinson and Latchem 2003 i), learners do most or all their learning from the materials alone (Phillips 2007). Therefore, DE materials largely determine the learning experience and success depending on the kind of approach to learning they encourage. According to Warren (2004), deep learning involves a critical analysis of new ideas, leading to understanding and long-term retention of these to be used for problem-solving in unfamiliar contexts. Learners using a deep approach draw on their background knowledge to develop their own understanding and interpretation of what they learn. Since UR-CE's DE materials are expected to engage teacher-learners' experience, help them apply the knowledge to their own situation and stimulate critical thinking (KIE 2009), learning activities in these materials should adopt a deep approach to learning. This is more so in teacher education, particularly because teachers need to adapt their teaching to ever-changing teaching/learning contexts.

\footnotetext{
${ }^{1}$ The chapter from Warren's (2004) book was accessed online from http://stbweb02.stb.sun.ac.za/tutors/documents/deep\%20and\%20surface\%20approaches\%20to\%20learning.pdf, on 10 October 2015. Page numbers are not indicated.
} 


\section{Methodology}

This article is drawn from a PhD study and is a case study (Gillham 2000; Hancock \& Algozzine 2006) of the University of Rwanda's DE materials for teachers of English and their responses to the original and modified versions of these. Textual analysis (Bloor \& Wood 2006; McKee 2005), which is one of two main sources of data for this study, focussed on content and mediation devices included in these materials. The analysis was conducted on Modules 1 (Introduction to Language and Linguistics) and 7 (French and English teaching methods): Module 1 because it was the first module with which the teachers engaged and had a subject content focus and Module 7 because it was the only module which aimed to address the teaching of English.

Teacher-learners' responses to both UR-CE's materials were obtained through 30 to 40 minutes semi-structured interviews (Corbetta 2003; Kajornboon 2005). The information that was sought was mainly teacher-learners' experiences with the UR-CE DE materials with a focus on a section in Module 7 that focused on writing pedagogy. The section on writing pedagogy was selected because writing has received less emphasis in the literature on language teaching than reading, speaking and listening (Ciobanu 2011; Ralfe 2009) while the ability to write well is central to success both in school and in the workplace (Norman \& Spencer 2005; Ralfe 2009). In addition, writing remains an overlooked area of investigation of teacher's knowledge (Hlas \& Hildebrandt 2010) and instruction in writing pedagogy for pre-service teachers is often limited (Norman \& Spencer 2005)

Nine respondents were selected from all the four regional centres where they have their bi-annual face-to-face sessions. Since the number of teacher-learners in the programme was far too high (599) for it to be feasible to interview them all, nine teacher-learners were selected using a combination of purposive and random sampling. The researcher concurs with Ning and Downing (2013) who indicate that students' learning experience has an influence on academic performance. Thus performance was taken as a basis for selecting teacher-learners who took part in this study. The researcher was guided by the tutors in the choice of informants from both high and low achieving categories. Learner 


\section{E. SIBOMANA}

performance, coupled with the need for countrywide representativeness led to the selection of two teacher-learners from each centre: one teacher-learner randomly selected from those with a relatively high level performance and another one from those with relatively low performance. The researcher intended to involve eight teacherlearners. However, one more teacher-learner volunteered to participate, bringing the total number to nine. One respondent elected to be interviewed in French, three chose Kinyarwanda (their mother tongue), and the rest preferred English. The interviews were conducted in the centres and were tape-recorded, transcribed and, where necessary, translated into English.

Thematic analysis (Braun \& Clarke 2006) was used to analyse teacher-learners' responses; these were grouped, analysed and interpreted according to the different themes identified. In this article, only one theme, learning activities, is explored. Pseudonyms are used in the discussion of findings from the interviews.

\section{Findings}

This section presents the findings of an analysis of the activities in the materials, focusing on what they are meant for, what they require learners to do and related learning implications. It also reports on and discusses teacher-learners' responses to UR-CE DE materials.

\section{The role of learning activities in UR-CE DE materials for teachers of English}

The textual analysis conducted on activities in the UR-CE DE materials indicates that these activities are of the self-assessment question type. The activities which are included in the materials are meant just for 'assessment of learning' purposes and, therefore, play a very limited 'teaching role' (Vrasidas 2000). For instance, the activities in the modules are introduced together with two 'types of assessment' (Tutor marked assignments and final exams) under the heading 'How will I assess my learning'. The following instructions to UR-CE DE teacher-learners regarding activities in the modules indicates their summative nature: 
In every block, there are activities meant to test how much you have learnt from each section. Attempt them after each section before moving on to the next block. If you find the activity difficult, read the section again and attempt it a second time. If the second attempt doesn't yield much, consult your colleagues or Subject Tutor (Module 1, 5).

This quote is in line with the instructions given to UR-CE DE materials designers regarding the role of activities: activities should enable teacher-learners "to assess their understanding of the block content" (KIE 2009, 15). The role of activities in exploring and extending learning is ignored in the UR-CE DE materials. Without attempting a comparative study, I would like to use the instructions given to learners in DE materials designed by Gultig and colleagues $(2001 ; 2010)$, which have been appreciated for their quality design². Gultig and Butler (2010) address teacher-learners as follows:

[W]e rely strongly on your participation in the activities we set which often require you to practise the ideas introduced in this module in your own school. We believe that our teaching style works best if you also try new ways of learning, rather than only concentrating on increasing what you know (2010, 4 , emphasis in the original).

Gultig (2001, 6-7) warns the users of Learners and Learning of the danger of ignoring learning activities as follows:

[O]f course you could complete this module in a couple of days if you ignore all the activities and simply read it from cover to cover. But this isn't studying and you will probably forget everything within days ... you will miss the most important part of the learning pathway we have developed for you.

\footnotetext{
${ }^{2}$ In his review of Learners and Learning, the director of the Centre for Research and Development at the Open University (UK) points out that the module is "an invaluable resource for those designing pre-service and professional courses for teachers" (Moon 2002, 27).
} 


\section{E. SIBOMANA}

Students who use the UR-CE materials and those using materials designed by Gultig and colleagues are likely to approach them differently with likely differences in learning outcomes, while both materials aim at training a competent teacher of the $21^{\text {st }}$ Century. While memorisation and remembering may be valued by the Rwandan society's learning culture, these are unlikely to help graduates from the system to compete in the global context.

Another indication that the activities in the UR-CE materials play a limited teaching role is that while the teacher-learners are instructed to read and understand the content of one section before moving to the following one, the presentation of content in subsequent sections does not refer in any way to the content, activity questions and feedback on previous sections. According to the instructions, completing an activity is supposedly a pre-requisite to continue to the next section, but it is not the case in practice. Such an approach ignores one important purpose of assessment: "to aid learners in their subsequent learning" (Rahman 2015, 96). The approach also contradicts Vygotsky's concept of mediation, which, according to Rogoff (1990), cited in Donato (1994), emphasises the teacher's (in the case of DE materials, the designer's) active continual revisions of previous learning in response to the emerging capabilities of the learner. Furthermore, it can be argued that some activities are set just to comply with the requirement of "at least one activity in each section" (KIE 2009, 15) as there is just one (not more) activity for each section irrespective of its length. For instance, there is one activity (5 questions) for a ten-page section on "Components of language" (Module 1, 53), one activity (1 question) for a five-page section on "Issues and Procedures in English Language Teaching" (Module 7, 20) and one activity (4 questions) for a half page section on "Writing system on the computer" (Module 1, 96).

\section{The learning approach encouraged by learning activities in UR-CE DE modules}

The learning objectives included in UR-CE DE materials mostly encourage teacherlearners to adopt a surface approach to learning: they generally expect them to state, define, explain, differentiate, classify, identify, etc. all of which require lower order thinking skills. For instance, learning objectives for Block 2 of Module 1 (The grammar of English) 
include (i) state the characteristics of nouns, (ii) describe different types of nouns, pronouns and determiners, (iii) explain the functions of pronouns and determiners and (iv) distinguish the different types of adjectives. This is despite the directive to materials designers to help teacher-learners "acquire more subject knowledge, develop their analytical and reflective capacity and improve the quality of their teaching" (KIE 2009, 1). These skills, Duron, Limbach and Waugh (2006) argue, are likely to develop when students are engaged in activities which require them to analyse, synthesise and evaluate different issues, concepts, theories, etc. It should be noted that some sections do not contain any learning outcomes, which is a cause for concern, given that specification of learning outcomes is likely to influence learners' engagement with learning materials. While UR-CE DE materials designers are requested to design activities which "challenge students to think more deeply, and to put concepts into context"(KIE 2009, 11), the activities in UR-CE DE materials for English predominantly consist of questions for which answers can be taken directly from the materials without much thinking. They generally ask for definitions and explanations presented in the content. For instance, the activity on a section on 'Sociolinguistics' (Module 1, 69) includes the following questions: (i) What is a dialect? (ii) What is a sociolect? (iii) What do you understand by the term dialectology? and (iv) Differentiate between sociolinguistics and the sociology of language. All these questions ask teacher-learners to reproduce definitions of sociolinguistics-related terms. Consequently, answering these questions correctly may not necessarily imply an understanding of what sociolinguistics is and of the effects of society on language use (and vice versa), which, according to the designers, is the essence of sociolinguistics (Module 1,69). As an example, the answer provided by the module designers to the fourth question is that "sociolinguistics focuses on the effect of the society on the language, while sociology of the language focuses on the effects of language on society" (Module $1,70)$. This answer does not help teacher-learners to understand the 'effects' and how they happen, to identify these in their linguistic community/ies and, more importantly, to incorporate and respond to these in their classes.

If activities in UR-CE DE materials are supposed to encourage teacher-learners to think deeply (KIE 2009), and the end aim of mediation is to enable learners to use acquired 


\section{E. SIBOMANA}

information to develop their independent thinking and problem-solving skills (see Williams \& Burden 1997), I suggest that the above activity questions should be improved. For instance, in addition to defining a dialect, teacher-learners could be asked to identify some Kinyarwanda dialects and, possibly, compare them to the standard dialect. The concept of 'world Englishes' could also be used to exemplify how the same language can be used (and owned) differently by different societies. Teacher-learners could also be asked to identify and explain some of the effects that society, its values, norms and changes therein have had on the use of Kinyarwanda. For instance, the militia that committed the 1994 genocide in Rwanda used to call itself 'Interahamwe' (people working together). The association of the word 'Interahamwe' with the 1994 genocide has changed its meaning to that of a 'serial killer'. Such examples could provide a better understanding by encouraging teacher-learners to relate content to their own personal world (Turuk 2008). A second example of an activity which promotes a surface approach to learning comes from Block 2 (The Grammar of English) of Module 1. Recent language teaching specialists (for example Gardner 2008; Wang 2010) suggest that grammar should be taught in context. Therefore, a lesson on pronouns should aim to enable learners to use these correctly and in context. However, this is not the approach taken by the designers.

The following is one activity on pronouns:

\section{Question 1}

In each of the following sentences, a pronoun has been highlighted. What type of pronoun is it?
a. Let's contact one another once we have made some progress.
b. She wants to do it herself.
c. I can't find them.
d. I can't believe it's finally ours.
e. The girl who usually cuts her hair has won the lottery.
f. He wants to go to Scarborough.
g. Why are you shouting at me?
h. Jim gave me the last copy.

i. Nobody said a word all night 


\section{Question 2}

Give the objective forms of the following pronouns
a. I
b. We
c. $\mathrm{He}$
d. She
e. They
f. Who

Since a table of the different types of pronouns is provided in the teaching text, learners can copy the pronouns and their types (for question 1) from the table without necessarily thinking about their use. Question 2 is even more problematic because the pronouns are not put in sentences. What teacher-learners need to do is to go back to the table and copy the corresponding objective forms. Thus, teacher-learners are not challenged to explicitly state the functions of the pronouns (which is the learning outcome of the section) or, more importantly, to use them in new contexts as a result of attempting the activity. In order to enable learners to use and explain the use of the pronouns, teacher-learners could have been asked to use these pronouns in their own sentences for question 1. Another alternative question could be to provide sentences or a text containing nouns and ask learners to replace them with pronouns and, if necessary, to name the type of pronouns they have chosen. For question 2 , the designers could have provided a text containing the same nouns (or names) used both as subjects and as objects in different sentences. Teacher-learners could then be asked to replace the nouns/names with personal pronouns, which could show whether or not they understand the difference between the two uses of pronouns.

The encouragement of surface rather than deep learning can also be identified in the pedagogy module (Module 7 ), which is expected to encourage theorised practice. The activities in this module do not generally take teacher-learners beyond reading and reproducing content in the module; they just require learners to identify or even copy answers directly from the materials. Some examples include 'what are the main objectives 
of the Direct Method?' (54), 'how does the Direct Method differ from the GT Method?' (54), 'what are the main criticisms levelled against the cognitive code method?' (63), 'give the name of the methods that are based on the Comprehension Approach' (76), 'what are the advantages of teaching your learners how to read with understanding' (98).

Moreover, even when questions seem to ask teacher-learners to think critically and give their opinion, the related feedback does not usually reflect this requirement. For instance, Activity 2 in block 1 (Module 7, 47) is as follows: Elaborate on any two of the following basic principles of language learning, making any critical comments based on your personal opinions. These principles (according to the module designers) are habit formation, accuracy, concreteness, proportion of different aspects of a course, to mention just a few. No answer is provided for this question. Instead, teacher-learners are referred to related 'feedback', which reads as follows: "this is an open-ended activity. You may summarize the ideas given for each principle from the above sections. But you are free to give your personal opinions on the issues involved" (47). This feedback implies that teacher-learners' opinion is optional, contrary to what is indicated by the question. I suggest that there should be at least an example illustrating (a) way(s) learners could engage with the question.

However, there are very few instances where questions do encourage critical thinking and feedback (through answers to activities questions) links up with, and responds to, the requirements of the questions. These include the following question: "[M]ention some of the barriers that students bring with them and show ways in which the teacher can overcome them other than ensuring a complete control of his/her classroom" (Module 7, 67). The answer to the question mentions some barriers (fear, hatred of the target language culture, anxiety, etc.) and suggests that teachers should make their lessons interesting by being friendly and using teaching aids that are interesting for learners to overcome these barriers. One could argue that instructing learners to make a second attempt if they find the activities difficult implies deep engagement. However, there is no indication of what learners will do differently during the second attempt. Thus, making 
repeated but similar attempts to complete a difficult activity may not necessarily lead to deep engagement with the content. The researcher suggests that learners should have been provided with different ways of approaching the questions, which could help them think from different perspectives.

\section{Teacher-learners' perceptions of the learning activities}

As explained above, a small number of teacher-learners in the UR-CE DE programme were asked to express their views on both UR-CE DE materials and a redesigned section. The aforementioned conceptualisation of 'teaching-learning' activities in the UR-CE DE materials for English as primarily for 'assessment of learning' purpose has resulted in some teacher-learners share this understanding. They appear to believe that activities in DE materials are meant just for assessment and use them only for this purpose. For instance, two interviewees (Mukamana and Gashumba) pointed out that they read the entire redesigned section without answering the learning activity questions; they answered these later without re-reading the content 'in order to see how much they had learnt'. By using the activities in this way, these teacher-learners missed a very important point: the presentation of content in this section continuously built on activities and related answers and feedback. Thus, by ignoring activities while reading the section, there are issues which the teacher-learners could not grasp well.

However, some informants' answers suggest that they understood the role of learning activities. For instance, Karangwa criticized activities in Module 7 as follows: "the activities which we have here, it is to ... it is like an exam in this module. It is like a very difficult exercise." ${ }^{3}$ By referring to the activities as an (final) exam, which he was not happy with, Karangwa seems to imply that they do not contribute much to learning. In addition, some informants' answers concur with the findings of textual and content analysis, indicating that the activities encourage a surface approach to learning, although they did not use these words. They expressed their responses in different ways: for Mugabo, the activities in UR-CE DE modules are 'theoretical' while writing is practical; for Mutabazi, they do not develop critical thinking while for Mukamana and Rukundo, they are not 'effective'

\footnotetext{
${ }^{3}$ Quoted verbatim.
} 
because they just require the copying of sentences from the modules without much thinking. For Ngarambe, the questions do not have anything to do with teaching and, therefore, are not important for someone training to be a teacher. This situation left some teacher-learners frustrated. For example, Mukamana said:

For me, if you have given a definition of writing, then at the end you ask learners to reproduce it and, for feedback to the question, you reproduce the same definition, it is a waste of time. You should set questions for which answers cannot be copied directly from the modules.

These remarks suggest that the informants understand that learning is not transmission of information and rote learning but learners' active and meaningful construction and application of knowledge (Yew et al. 2016). In other words, they understand that they, as learners, have a central and active role in their learning and teacher educators are responsible for encouraging this through DE materials. So in addition to helping them to understand what is expected of them as learners, teacher education materials are supposed to help them understand their role as teachers.

Teacher-learners' answers reveal another important point seen through what Ndahayo expects from activities: to remind the learner of the most important things in the materials. This echoes Rowntree's (1990) recommendation that each important idea in teaching material should be made a subject of an activity. In other words, if teacher-learners want to know and understand what is important in the section, one option available to them is to look at the related activities. Indeed, some studies (for example, Biggs 2007; Liu 2007) indicated that some (distance) students tailor their reading primarily to the assessment tasks. Therefore, when the activities do not cover all the content as is the case with some sections in UR-CE DE modules for English, teacher-learners may overlook some important issues. Indeed, as Biggs $(2007,3)$ argues, citing Ramsden (1992), "the assessment is the curriculum, as far as the students are concerned. They will learn what 
they think they will be assessed on, not what is in the curriculum, or even on what has been 'covered' in class".

\section{Discussion}

While learning activities are supposed to help learners "engage with content rather than merely reading about it"(Rowntree 1990, 83) and should encourage active and deep learning, notably by engaging learners in problem-solving strategies (Lockwood 1997), UR-CE DE approach to teaching does not comply with these requirements.

The analysis reported in this article indicates that 'learning activities' in UR-CE DE materials for English are just meant for assessment and generally expect learners to operate as decoders (Freebody \& Luke 1990) and encourage them to adopt a surface approach to learning (Biggs 1987). Thus they seem inappropriate in a teacher education programme: they are unlikely to encourage critical thinking and a deep understanding of the content that teacher-learners are learning. The approach taken by the designers contradicts the deep approach to learning which is officially encouraged by the University of Rwanda's College of Education (KIE 2009) in such guidelines as "stimulate, provoke, and challenge students to acquire new skills and knowledge" (KIE 2009, 2), "challenge students to think more deeply, and to put concepts into context" (KIE 2009, 11) and help learners "apply knowledge to their situation" (KIE 2009, 2). Surface approach, Czerkawski (2014) and Niyibizi et al. (2018) argue, fails to prepare learners adequately to overcome tomorrow's economic, technological, and societal challenges and thereby take part in socio-economic transformation. One reason for this is that it just encourages the reproduction of what learners learn without internalizing it or relating it to what they already know (Warren 2004).

The teacher-learners interviewed were frustrated by the low level intellectual demand of many of the activities in the UR-CE DE materials. This frustration confirms Vygotsky's suggestion that instruction located at or below learners' current level of understanding is not challenging enough to promote further development (Lui 2012). These informants seem to understand that a teaching/learning approach that encourages rote learning is 
likely to produce dull and uninspired learners (Simister 2004 as cited in Turuk 2008). Conversely, they were interested in activities which encourage/challenge them to move beyond mere reading of the modules and to consider various perspectives on the issues addressed in the modules. Their answers suggest that, as teachers, they understand that teaching should not just be about giving information to learners but should also challenge and help them to analyze, construct and reconstruct the information progressively (Donald, Lazarus \& Lolwana 2010; Jordan \& Pillay 2009) and to test and make judgments about the acquired knowledge, being open to alternative ways of thinking (Wheelahan 2010). Thus as some of these teacher-learners indicated, with the current UR-CE DE materials, they may pass the exams and get degrees but still fail to make a difference in the way they teach. As a result, they indicated that after getting the degrees they would have to find ways of acquiring the knowledge which they expected to (but did not) find in the programme. Some of them expressed their views as follows:

But here I haven't seen any example that can inspire a teacher [in teaching writing]. It implies that expecting changes in our teaching habits as a result of reading these modules is an illusion (Mukamana).

Even if I put everything in this module [the language pedagogy module] in my head, I will not be able to teach writing. As a teacher-learner, I go to school to study how to teach other people [how to write]. And when I arrive there, the module shows me the type of writing is this, but how to teach writing in the classroom there isn't. That is a very big problem. You can read and finish the whole UR-CE pedagogy module without understanding how to write an essay (Kalisa, quoted verbatim).

And you still find that ... though you may pass the exams, you cannot say that you understand the content effectively. We will still need to find more knowledge from elsewhere so as to be able to teach effectively (Karangwa).

The above participants' views concur with the findings of a study conducted on assessment practices in UR-CE's on-campus programmes (Niyibizi et al. 2018). This 
study indicated that assessment practices heavily encourage surface approach to learning, with limited focus on the socioeconomic transformative knowledge. In his research on challenges faced by Rwanda postgraduate students in an English medium university, Sibomana (2016) found that the students' undergraduate learning experiences did not emphasise critical thinking. This situation suggests that even the lecturers who designed these materials were under the influence of the surface learning culture in the country's education. Thus, the challenge may not necessarily be addressed from the materials design perspective but should be looked at from the overall education system's perspective.

\section{Conclusion}

Learning activities constitute an important element in instructional materials, particularly in self-instructional materials. They indicate to the learners, who are teaching themselves (or learning on their own), what is expected of them in the materials and, to an extent, what successful learning means. Thus, care needs to be taken while designing them so that they are aligned to the goals of the learning programme. The activities in the UR-CE DE materials for English appear not to help learners to achieve the goals of their education programme because they focus almost entirely on summative assessment and encourage a surface approach to learning. The teacher-learners interviewed about their response to these materials expressed dissatisfaction with this approach. Therefore, it is recommended that the university re-designs the materials in order to encourage deep learning and allocates resources of design expertise and adequate time for designing. Such redesigning is important especially now that distance education has been given a key role in achieving the country's economic visions 2020 and 2050 and in meeting the United Nations' sustainable development goals (SDGs). In Rwanda, as elsewhere, for these to be achieved, the promotion of critical thinking skills is mandatory and likely to be achieved only when teaching and learning approaches adopted in distance education materials encourage students to apply critical thinking to what they learn. While findings from one case study cannot be generalized to others, it may be possible to offer some 'fuzzy generalizations' (Bassey 1999). Therefore, the University of Rwanda's DE programme as discussed in this article can offer lessons to other institutions. 


\section{References}

Abedi, M. \& Badragheh, A. 2011. Distance Education in Developing Countries. Journal of American Science, 7(4) 295-301.

Bassey, M. 1999. Case Study Research in Educational Settings. Buckingham: Open University Press.

Biggs, J.B. 1987. Student Approaches to Learning and Studying. Victoria: Brown Prior Anderson.

Biggs, J.B. 2003. 'Aligning Teaching and Assessing to Course Objectives'. Paper Presented at a Conference on Teaching and Learning in Higher Education, University of Aveiro, 13-17 April, 2003.

Biggs, J. B. 2007. Aligning teaching for constructing learning. The Higher Education Academy. [Online] Available from: https://www.heacademy.ac.uk/ system/files/resources/id477 aligning teaching for constructing learning.pdf [accessed 17 September 2017].

Biggs, J. and C. Tang. 2009. Applying constructive alignment to outcomes-based teaching and learning. [Online] Available from: http://drij.uitm.edu.my/DRJJ/ MQAGGPAS-Apr2011/What-is-CA-biggs-tang.pdf [accessed 17 September 2017].

Bloor, M. and F. Wood. 2006. Keywords in Qualitative Methods: a Vocabulary of Research Concepts. London: Sage Publications.

Braun, V. and V. Clarke. 2006. Using thematic analysis in psychology. Qualitative Research in Psychology 3(2), 77-101.

Christensen, C. M., M. B. Horn, and C.W. Johnson. 2008. Disrupting class: How disruptive innovation will change the way the world learns 98. New York: McGrawHill.

Ciobanu, I.R. 2011. Developing writing skills for business purposes in mixed-ability classes. Studii si Cercetari Filologice. Seria Limbi Straine Aplicate 10, 112-117.

Corbetta, P. 2003. Social Research Theory, Methods and Techniques. London: SAGE Publications. 
Czerkawski, B.C. 2014. Designing Deeper Learning Experiences for Online Instruction. Journal of Interactive Online Learning, 13(2), 29-40.

Donald, D., S. Lazarus, and P. Lolwana. (2002). Educational Psychology in Social Context ( $\left.3^{\text {rd }} E d\right)$, Oxford: Oxford University Press.

Duron, R., B. Limbach, and W. Waugh. 2006. Critical Thinking Framework For Any Discipline. International Journal of Teaching and Learning in Higher Education, 17(2), 160-166.

Freebody, P., and A. Luke. 1990. Further Notes on the Four Resources Model. [Online]

Available from: http://kingstonnetworknumandlitteam.wikispaces.com/file/view/

Further+Notes+on+the+Four+Resources+Model-Allan+Luke.pdf [accessed 10 August 2017].

Fung, Y.Y.H. 2005. Teachers' views on and use of printed materials in a distance learning teacher education course. Open Learning 20(2), 175-183.

Gardner, S. 2008. Changing approaches to teaching grammar. ELTED 11, 39-44.

Gillham, B. 2000. Case Study Research Methods. London: Continuum.

Gultig, J., ed. 2001. Learners and Learning: Learning Guide. The SAIDE Teacher Education Series. Johannesburg: SAIDE.

Gultig, J. and D. Butler, eds. 2010. Creating People-Centred Schools: School Organization and Change in South Africa. The SAIDE Teacher Education Series. Johannesburg: SAIDE.

Hancock, R.D. and B. Algozzine. 2006. Doing Case Study Research: A Practical guide for Beginning Researchers. New York: Teacher College Press.

Howard, R. and I. McGrath, eds. 1995. Distance Education for Language Teachers: a UK perspective. Adelaide: Multilingual Matters.

Jordan, S. and R. Pillay. 2009. Beginning my Journey of Professional Development: The language Teacher and the Teaching profession. In Teaching Language. Edited by A. Ferreira. pp. 1-9. Northlands: MacMillan South Africa.

Kajornboon, A.B. 2005. Using interviews as research instruments. E-Journal for Researching Teachers, 2(1). [Online] Available from: http://www.culi.chula.ac.th/ Research/e-Journal/bod/Annabel.pdf [accessed 10 August 2017]. 
Kember, D. 1996. The Intention to both Memorize and Understand: Another Approach to Learning? Higher Education 31, 341-354.

Kigali Institute of Education. 2009. A Handbook for Course Writers. Unpublished Handbook, Kigali Institute of Education.

Kigali Institute of Education. 2010. English Module 1: Introduction to Language and Linguistics. Kigali: Kigali Institute of Education (KIE).

Kigali Institute of Education. 2010. Education Module 7: French and English teaching methods. Kigali: Kigali Institute of Education (KIE).

Liu, S. 2007. Assessing asks in online courses. In Encyclopedia of Distance Learning, $2^{\text {nd }}$ Ed. Edited by P. L. Rogers et al. [Online] Available from: DOI: 10.4018/978-1-60566198-8.

Lockwood, F. 1992. Activities in Self-Instructional Text. London: Kogan Page.

Lockwood, F. 1997. Developing Self-Instructional Material, For Open, Distance and Flexible Learning. Pre ICDE Conference Workshop Report, Pennsylvania State University.

Lusunzi, I. S. 1999. Building instructional Activities in Distance Education SelfInstructional Materials. A paper presented at the $1^{\text {st }}$ NADEOSA Conference, 11-13 August 1999.

McKee, A. 2005. Textual analysis: a beginner's guide. London, California, New Delhi: Sage Publications Ltd.

Mishra, S. and A.K. Gaba. 2001. How do Distance Learners use activities in SelfInstructional Materials? Indian Journal of Open Learning, 10(1), 40-51.

Moon, B. 2002. Learners and Learning: A Review. Open Learning Through Distance Education (OLTDE), Tenth Anniversary Edition, July 2002, p. 27.

Murdoch, G. 1994. Language development provision in teacher training curricula. ELT Journal 48(3), 253-265.

Ning, H.K. and Downing, K. 2013. Influence of student learning experience on academic performance: The mediator and moderator effects of self-regulation and motivation. British Educational Research Journal, 38(2), 219-237. 
Niyibizi, E., Sibomana, E., Niyomugabo, C., Yanzigiye, B., Amini Ngabonziza J.D. \& Perumal, J. 2018. Assessment in a Rwandan higher education institution: a quest for aligned assessment to promote socio-economic transformation.

Assessment \& Evaluation in Higher Education. [Online] Available from: DOI: 10.1080/02602938.2018.1436688

Norman, K.A and B.H. Spencer. 2005. Our lives as writers: examining pre-service teachers' experiences and beliefs about the nature of writing and writing instruction. Teacher Education Quarterly 32(1), 23-40.

Phillips, J. A. 2007. Writing Self-Instructional Materials for Distance Learners: An Introspective Study. A paper presented at the $21^{\text {st }}$ Asian Association of Open Universities (AAOU) Annual Conference, Kuala Lumpur, 29-31 October 2007.

Race, P. 1992. 53 Interesting Ways to Write Open Learning Materials. Bristol: Technical and Educational Services Ltd.

Rahman, M. H. 2015. Learning assessment in a self-learning material. International Journal on New Trends in Education and Their Implications 6(3), 95-101.

Ralfe, E. 2009. From the Creative to the Transactional and everything in-between: Teaching Writing. In Teaching Language. Edited by A. Ferreira, pp. 148-176. Northlands: Macmillan South Africa.

Robinson, B. and Latchem, C. (2003). Open and distance teacher education: Uses and models. In B. Robinson and C. Latchem (Eds). Teacher Education Through Open and Distance Learning (pp. 28-47). London and New York: Routledge, Falmer.

Rowntree, D. 1990. Teaching through Self-Instruction: How to Develop Open Learning Materials. London: Kogan Page.

Shabani, J. and P. Okebukola. eds. 2001. Guide to the Development of materials for Distance Education. Ibadan: Olu Akin Printing.

Sibomana, E. 2016. 'We know what to say, we know what to write, but we don't know how': the challenges of becoming academically literate in a new linguistic and sociocultural space. Education As Change. [Online] Available from: DOI: http://dx.doi.org/10.17159/1947-9417/2016/747 
Smith, A. \& Smith, E. 2006. Learning for Success: Distance Education Students' use of their Learning Materials. Journal of University Teaching \& Learning Practice, 3(1), Article 5.

Struyven, K., F. Dochy, and S. Janssens. 2002. Students' perceptions about assessment in higher education: A review. Paper presented at the Joint Northumbria/Earli SIG Assessment and Evaluation Conference, August 2002, in University of Northumbria, Newcastle.

Swales, C. 2000. Editing Distance Education Materials. Vancouver, BC: Commonwealth of Learning.

Tenenbaum, G. et al. 2001. Constructivist pedagogy in conventional on-campus and distance learning practice: an exploratory investigation. Learning and Instruction 11, 87-111.

Turuk, M.C. 2008. The Relevance and Implication of Vygotsky's Sociocultural Theory in the Language Classroom. ARECLS 5, 244-262.

Vrasidas, C. 2000. Constructivism versus objectivism: Implications for interaction, course design, and evaluation in distance education. International Journal of Educational Telecommunications 6(4), 339-362.

Wang, F. 2010. The Necessity of Grammar Teaching. English Language Teaching, 3(2), 78-81.

Warren, H. 2004. Engineering Subject Centre Guide: Learning and Teaching Theory for Engineering Academics. Loughborough: HEA Engineering Subject Centre.

Wheelahan, L. 2010. Why Knowledge Matters in Curriculum: a Social Realist Argument. London/New York: Routledge.

Williams, M. and R. Burden. 2007. Psychology for Language Teachers: A Social Constructivist Approach. Cambridge: Cambridge University Press.

Yew, T.M. et al. (2016). Stimulating Deep Learning Using Active Learning Techniques. Malaysian Online Journal of Educational Sciences, 4(3), 49-57.

Zarei, G.R. 2008. The effect of constructivist language teaching/learning on students' conceptions of L2 reading. Iranian Journal of Language Studies (IJLS) 2(2), 281298. 